\title{
Does Social Comparison Orientation Moderate the Organisational Justice, In-role Performance, Citizenship and Counterproductive Behaviours Relationship?
}

\author{
Sahar Mohamed Badawy ${ }^{1} \&$ Sherine Fathy El-Fekey ${ }^{1}$ \\ ${ }^{1}$ Business Department, British University in Egypt, Cairo, Egypt \\ Correspondence: Sahar Mohamed Badawy, Business Department, Faculty of Business Administration, \\ Economics and Political Sciences, British University in Egypt. El Sherouk City, Suez Desert Road, Cairo, Postal \\ No. 11837 - P.O. Box 43, Egypt. E-mail: sahar.badawy@bue.edu.eg
}

Received: October 12, 2017

Accepted: October 28, 2017

Online Published: November 20, 2017

doi:10.5539/ijbm.v12n12p181

URL: https://doi.org/10.5539/ijbm.v12n12p181

\begin{abstract}
This paper aims at (1) investigating the relationship between Organisational Justice and three dimensions of employees' performance namely; In-role performance, Citizenship Work Behaviours and Counterproductive Work Behaviours within the Egyptian Context, (2) investigating the moderating effect of Social Comparison Orientation on the Organisational Justice-Performance relationship with regard to the three dimensions of performance. The theoretical foundations of the proposed relationships were discussed. Using a structured questionnaire to assess research variables, a quota sampling procedure was used to recruit a sample $(\mathrm{N}=298)$ from managers working in public and private organisations in the greater Cairo Area. The three parts questionnaire was tested for validity and reliability. The proposed relations were tested using Pearson correlation coefficient and multiple regression analysis with the interaction effect between the standardized scores $(\mathrm{Z})$. Results supported the significant relationship between Organisational Justice and In-role performance, Citizenship Work Behaviours and Counterproductive Work Behaviours. Results also supported the moderation role of Social Comparison Orientation. Theoretical and practical implications and future research were addressed.
\end{abstract}

Keywords: citizenship work behaviours, counterproductive work behaviours, Egyptian managers, in-role performance, organisational justice, social comparison orientation

\section{Introduction}

Organisational justice has attracted researchers' attention over the last three decades. How employees perceive organisational justice; how fairly and equally they are treated, is very crucial as it affects employees' behaviour, attitudes and performance (Swalhi, Zgoulli, \& Hofaidhllaoui, 2017).The link between perceived organisational justice and employee performance and behaviours is well recognized (Cohen \& Spector, 2001) through social exchange theory, where fair treatment of employees stimulates an obligation for employees to reciprocate the organization (Aryee, Budhwar, \& Chen, 2002).

Perceived justice may lead to positive outcomes; like achieving expected in-role performance, participating in positive extra-role behaviours, and increase in employees' satisfaction and commitment (Burney, Henle \& Widener, 2009). While perceived injustice may lead to direct and indirect negative outcomes. Direct outcomes may include employees' participation in counterproductive behaviours (Wu, Sun, Zhang, \& Wang, 2016), intentions to leave (Aryee et al., 2002), and decrease in productivity and profitability (Kelloway, Francis, Prosser \& Cameron, 2010). Indirect outcomes may include decrease in customer satisfaction and might lead to damaging the company reputation (Kelloway et al., 2010). These serious consequences stimulate the increasing interest in studying not only the effects of perceived organisational justice on employees' performance and behaviours, but also the variables that may affects this relationship (Colquitt, Conlon, Wesson, Porter, \& Ng, 2001).

Most of researchers studied the effect of perceived organisational justice (POJ) on either in-role performance or extra-role behaviours (Colquitt et al., 2001). This distinction between in-role and extra-role performance helps decision makers in getting the best of their employees and capture both the positive and negative sides of employee' extra-role performance presented in citizenship behaviours and counterproductive behaviours 
(Rotundo \& Sackett, 2002). Recent researches extends the scope of employees' performance to include the three dimensions; in-role performance, citizenship behaviours and counterproductive behaviours (Dalal, 2005) (Sackett, 2002; Miles, Borman, Spector, \& Fox, 2002; Rotundo \& Sackett, 2002; Devonish \& Greenidge, 2010) and called for more investigation on the effect of OJ on these three performance' dimensions in different contexts (Devonish \& Greenidge, 2010; Miles et al. 2002; Swalhi et al., 2017) especially within the limited researches available in the Arab world (Elamin \& Tlaiss, 2015; Al-Quraan \& Khasawneh, 2017). This current research responds to this call by examining the effects of POJ on employees' performance with its three dimensions in a new context (private and public organizations in Egypt).

The interest in justice-performance relationship has also extended to include several moderators that affect this relation including ability-based emotional intelligence, trust in organization and in supervisors, equity sensitivity, burnout, individual differences, power distance and individualism (Or \& Aharon, 2017; Devonish \& Greenidge, 2010; Aryee et al., 2002; Blakely, Anderws \& Moorman, 2005). However, researchers did not consider a critical variable that could affect this relation which is the tendency to compare (social comparison). Social comparison theory presented by Festinger's (1954) suggests that individuals engage in series of comparisons with others in order to get a clearer picture of self-evaluation (Buunk, Zurriaga \& Peíró, 2005). This tendency toward social comparison is expected to affect the justice-performance relationship, where individuals with high tendency for social comparisons will react differently to perceived justice than those with law tendency for social comparisons (Moon, Lee, \& Oah, 2017).

This paper aims at investigating the moderating effect of social comparison orientation on the justice-performance relationship with regard to the three dimensions of performance; in-role performance, citizenship behaviours and counterproductive behaviours. Introducing social comparison orientation as a moderator in the justice-performance relationship is considered the research main contribution along with the use of the integrated model for performance in new context.

\section{Literature Review}

\subsection{Organisational Justice (OJ)}

Organisational justice has been always a human and organisational concern not only because of its benefits to the organization but also because of the negative out comes that may harm the organization in case of injustice (Colquitt et al. 2001). The importance of organisational justice increases in developing countries where resources are limited and sensitive to any change in wages and rewords (Elamin \& Tlaiss, 2015), which makes organisational justice a critical factor to maintain employees. The roots of organisational justice can be tracked back to 1963 when Adams presented the equity theory (Cohen \& Spector, 2001). Organisational justice is seen as the perceived fairness within an organisational setting (Devonish \& Greenidge, 2010). Organisational justice (OJ) has three dimensions; distributive, procedural and interactional justice.

Distributive Justice (DJ) is defined as "the perceived fairness of the outcomes one receives from social exchange or interaction" (Nowakowski \& Conlon, 2005, p. 5). DJ was developed by Adams (1963) who suggested that fairness is evaluated as a result of the ratio between employees' inputs and their outputs that is in contrast with the perceived inputs and outputs of comparable employees (Devonish \& Greenidge, 2010). Procedural Justice (PJ) refers to the perceived fairness of the decision making process used to determine the obtained outcomes (Nowakowski \& Conlon, 2005), as employees concern about the procedures through which they got their outcomes as much as the outcomes themselves (Swalhi et al. 2017). Interactional Justice (IJ) emerged as a reflection of the emphasis on the 'human element' in the organisational context (Devonish \& Greenidge, 2010). It refers to the perceived fairness of interpersonal treatment from the decision makers or those who administered the procedures used to reach those outcomes (Devonish \& Greenidge, 2010). Interactional justice includes interpersonal and informational justice (Colquitt et al., 2001).

Organisational justice has been linked to different organisational outcomes (Aryee et al., 2002) among which employee performance might be the most important outcome (Cohen \& Spector, 2001). OJ was found to affect employee performance in different directions. Perceived justice has a positive impact on employees' in-role performance and employees' citizenship behaviours (Blakely et al. 2005; Burton, Sablynski \& Sekiguch, 2008), whereas it has a negative effect as it increases employees' counterproductive behaviours (Dalal, 2005; Cohen \& Spector, 2001; Kelloway et al., 2010).

\subsection{In-Role Performance}

Employee performance was traditionally limited to the fixed formal tasks assigned to employees based on their job description, referred to in the literature as 'Task Performance' or 'In-role Performance' (Rotundo \& Sackett, 
2002). In-role performance refers to "behaviours that are recognized by formal reward systems and are part of the requirements as described in job descriptions" (Williams \& Anderson, 1991, p.606). It includes all formal tasks, duties, and responsibilities included in a job description (Griffin, Neal \& Parker, 2007). Traditionally in-role performance was evaluated in terms of proficiency, efficiency and productivity with which an individual carry out the required tasks and objectives (Rotundo \& Sackett, 2002). Hence, a specific well prepared job description is a must to evaluate employees' in-role performance (Griffin et al., 2007). Several factors were found to affect in-role performance including; job involvement, trust, leadership, management control, perceived support, psychological contract fulfilment, satisfaction and organisational justice (Griffin et al., 2007; Cohen \& Spector, 2001; Colquitt et al., 2001; Devonish \& Greenidge, 2010).

\subsection{Organisational Citizenship Behaviours}

Originally, the term Organisational Citizenship Behaviours (OCB) was given to Katz's (1964) category of extra-role behaviour (Organ, Podsakoff, \& MacKenzie, 2006). Later on Organ offered a formal definition where OCB represents "individual behaviour that is discretionary, not directly or explicitly recognized by the formal reward system, and in the aggregate promotes the efficient and effective functioning of the organization" (Organ et al., 2006, p. 3). OCB was explained by social exchange theory (Blakely et al. 2005; Burton et al. 2008), where satisfied employees tends to reciprocate the organization by giving more efforts and time than the required as a sign of gratitude to the organization for fulfilling employees' expectations (Aryee et al., 2002).

OCB has been identified by different category-based models into diverse dimensions one of which is Organ's (1988) five distinct dimensions: altruism, courtesy, conscientiousness, civic virtue, and sportsmanship (Organ et al., 2006). Organ's dimensions have been criticized due to the overlap and high correlations between the 5 dimensions which suggest that they are in fact one latent variable (LePine, Erez, \& Johnson, 2002). Hence, other experimental and theoretical work proposed two broad categories according to the intended beneficiary: citizenship behaviours directed to the organization (OCB-O) and citizenship behaviours directed to individuals (OCB-I) (LePine et al., 2002; Dalal, 2005). This model suggests that behaviours such as conscientiousness, civic virtue and sportsmanship are attempted to benefit the organization; whereas altruism and courtesy are attempted to benefit members of the organization. Recently, this model gained more support and proved to be more reliable (LePine et al. 2002). OCB was linked to different positive organisational factors and attitudes including; employees' satisfaction, perceived supervisors support, commitment, and perceived organisational justice as a kind of reciprocate for the organization (Organ et al. 2006).

\subsection{Counterproductive Work Behaviours - CWB}

Back in the 90s, Robinson and Bennett defined CWB as "voluntary behaviour that violates significant organisational norms and in so doing threatens the well-being of an organization, its members, or both" (Robinson \& Bennett, 1995, p.556). Many researchers support defining CWBs as actions that employees may commit to intentionally harm their organizations and/or its members (Dalal, 2005; Spector \& Fox, 2010). Examples of counterproductive behaviours include employee theft, sabotage, drug abuse, employee withdrawal, and aggression (Spector \& Fox, 2010). The wide range of counterproductive behaviours and the different nature of each form lead researchers to study each form separately leading to a large number of researches. Hence researchers started to think about more general classifications and introduced one general factor called "counterproductivity" with two main subcategories: organisational deviance and interpersonal deviance (Robinson \& Bennett, 1995). Recently, researchers supported the existence of two distinguished dimensions: counterproductive work behaviours directed toward organization itself (CWB-O) (e.g.. absenteeism, sabotage, theft, tardiness, long breaks, property damage, drug and alcohol use, and sloppy work); and counterproductive work behaviours directed toward individuals in organizations (CWB-I) (e.g. gossip, making fun of colleagues, physical assault and harassment), (Robinson \& Bennett, 1995; Sackett, 2002).

CWB and OCB were considered as two faces for the same coin as both are extra-role behaviours that are discretionary and not recognized by the formal system (Dalal, 2005; Miles et al. 2002; Sackett, Berry, Wiemann $\&$ Laczo, 2009). The argument that OCB and CWB are multidimensional including organisational and individual oriented job behaviours has been empirically supported by a growing recent body of research (Sackett et al. 2009; Spector \& Fox, 2010). Based on this distinction, researchers (Dalal, 2005; Spector \& Fox, 2010) argue that employees could engage in both CWB and OCB depending on the situation.

\subsection{Organisational Justice (OJ)-Performance Relationship}

Perception of justice and equity have been mostly studied in relation to performance based on social exchange theory (SET) which examines forms of human exchange (Rupp \& Cropanzano, 2002). According to SET subjective cost-benefit analysis is the basis for any human relationship (Aryee et al., 2002). According to the 
agent-system model of justice, people usually react towards the source of perceived justice or injustice, which could be the organization or its' members (Jones, 2009). Hence, employees' perception of justice is crucially important in studying the relationship between OJ and employee positive performance (in-role and OCB) and negative performance (counterproductive). However, the different dimensions of justice have different effects on performance (Devonish \& Greenidge, 2010; Elamin \& Tlaiss, 2015).

According to equity theory, perception of unfair distribution of work rewards creates tension within individuals where they try to resolve (Devonish \& Greenidge, 2010). But individuals also seek to minimize their losses so they do not prefer to reduce their in-role performance as it is directly linked to their rewords (Griffin et al. 2007), so they tend to use discretionary behaviours (OCB and CWB) as a reaction to fair/ unfair distribution of rewards (Devonish \& Greenidge, 2010; Chernyak-Hai \& Tziner, 2014; Saleem \& Gopinath, 2015).

The Procedural justice- performance relationship lays in the psychological contract theory, where individuals expect procedures used in evaluation and decisions making within the organization to be fair as part of their psychological contract (Saleem \& Gopinath, 2015). When procedures perceived as unfair, they consider it as a justifiable reason to reduce their in role-performance and OCB or to involve in CWB (Saleem \& Gopinath, 2015). PJ was found to explain variance in CWB and OCB directed to the organization not to individuals (Jones, 2009). Unlike distributive and procedural justice, interactional justice affects only extra-role behaviours and not in-role behaviours (Devonish \& Greenidge, 2010; Zapata-Phelan, Colquitt, Scott \& Livingston, 2009). When individuals perceive that they were treated unfairly by their supervisors or decision makers they feel angry and disappointed and try to get revenge through reducing their OCB and involving in CWB. However, interactional justice was found to predict OCB and CWB directed to individuals not to the organization (Jones, 2009).

The organisational justice-performance relationship was supported, where direct significant positive effects on both in-role performance and OCB and a negative effect on CWB were found (Saleem \& Gopinath, 2015; Devonish \& Greenidge, 2010). However, researchers claimed that the (in)justice-CWB relationship might be stronger than the justice-OCB relationship (Jones, 2009; Dalal, 2005; Devonish \& Greenidge, 2010). Others argue that in-role performance will not be affected by perceived justice or injustice based on the economic aspect of the social exchange theory exchange (Aryee et al. 2002; Zapata-Phelan et al. 2009). Therefore, this research aims at investigating this relationship in the Egyptian context through the following hypotheses:

H1: There is a positive significant relationship between organisational justice and in-role performance.

$\mathrm{H} 2$ : There is a positive significant relationship between organisational justice and OCB.

H3: There is a negative significant relationship between organisational justice and CWB.

\subsection{The moderating role of Social Comparison Orientation (SCO)}

Several researchers (Miles et al. 2002; Aryee et al. 2002; Blakely et al. 2005) have raised the question: what are the factors that may affect employees' tendency to react to organisational justice / injustice? In their attempt to answer these questions several mediators and moderators were introduced. Two approaches were used; the first concentrated on organisational variables and attitudes (Saleem \& Gopinath, 2015; Chernyak-Haia \& Tzinera, 2014), and the second concentrated on personal traits and characteristics (Jones, 2009; Spector \& Fox, 2010; Wu et al., 2016).

A new approach was introduces using social comparisons theory. Few researchers (Spence, Ferris, Brown, \& Heller, 2011; Greenberg, Ashton-James, \& Ashkanasy, 2007; Goodman \& Haisley, 2007; Buunk et al., 2005) used social comparison processes to explain several key areas of organisational context including: organisational justice, performance appraisal and affective behaviour in the workplace. Researchers (Collie, Bradley \& Sparks, 2002; Spence et al., 2011) argue that most of the models introduced to explain organisational justice and employees' behaviours were inspired by the social exchange theory which added great value to our understanding, yet, it does not explain under what circumstances employees engage in these behaviours (Spence et al. 2011). Inspired by this approach, this current research introduces social comparison orientation as a moderator in the relationship between organisational justice and in-role performance, OCB and CWB.

The theory of social comparison goes back to 1954 when Festinger introduced it as a source of information for self-evaluation (Festinger, 1954). According to Festinger, social comparison is a natural and vital human need where people assess their opinions and abilities against similar others (Festinger, 1954) especially when there is a lack of objective physical standards (Goodman \& Haisley, 2007). Social comparison refers to the process of thinking about information regarding one or more other people's ability and opinion in relation to one's own ability and opinion (Goodman \& Haisley, 2007). Social comparison theory has gone through many transitions and reconstructions where it originally started as a self-evaluation process within a group; to become a wider 
field of study that includes multiple views and approaches (Buunk et al., 2005).

Festinger's (1954) initial perspective was that an individual will be motivated to look upward and compare with superior others; for the sake of inspiration and self-improvement (Festinger, 1954). Later research has discovered that as much as this informative comparison can be encouraging, it can also be threatening as it indicates that this person is doing poorer than the compared superior (Goodman \& Haisley, 2007). Such results have drawn the attention to study downward comparisons as well (Buunk et al., 2005). Subsequent research has acknowledged that people are actually engaged in the two social comparison directions - upward and downward comparisons; and they are considered two distinct constructs (Goodman \& Haisley, 2007).

The positive and negative effects of social comparison theory have been investigated (Buunk et al. 2005). It was originally assumed that one would experience a negative frustrating feelings, decrease in self-image and self-efficacy after upward comparisons as a result of comparing with a better-off others (Guimond, Chatard, Martinot, Crisp, \& Redersdorff, 2006). This negative effect can be explained by the Contrast effects which occur when an individual not only focuses on the dissimilarities between her/himself and the compared target; but also exclude the possibility of becoming similar to the target in the future (Buunk et al., 2005). Hence, comparing upwards puts one in contrast to someone better off which induces negative feelings; whereas comparing downwards puts one in contrast to someone worse off which produce positive feelings (Guimond et al., 2006).

On the other hand, one would have positive motivational boosts and higher self-esteem as a result of downward comparison and thus higher self-confidence (Guimond et al. 2006). This is explained by the Assimilation effects. Assimilation effects happen when an individual concentrates on what is common between her/himself and the compared target; and assumes that s/he could resemble that target in the future (Buunk et al. 2005). Those feelings of resemblance with the other's destiny may cause an individual to experience the same feelings of the other's - whether good or bad (Buunk et al., 2005). That is upward comparison will generate positive feelings as one would enjoy the success of the other; while downward comparison produce negative feelings as one would sympathize with the grief of the other (Guimond et al., 2006). It has been proven throughout the literature that contrast and assimilation effects may exist with both upward and downward comparisons (Goodman \& Haisley, 2007). Taking into consideration the highly competitive environment, it is argued that contrast effect is more dominant in social comparisons than assimilation effects (Buunk et al., 2005).

The link between Organisational justice and social comparison is clear in their roots as justice theory was built on the equity theory proposed by Adams (1965) who was inspired by Festinger's (1957) social comparisons theory (Goffin, Jelley, Powell \& Johnston, 2009; Kim, Edwards \& Shapiro, 2015). Both theories share the same hypothesis in which they assume that individuals conduct comparison. In equity theory individuals compare their inputs and outputs with some referent others' who are mainly at the same level for the aim of evaluating the fairness of their outcomes (Cohen \& Spector, 2001), whereas in social comparisons theory individuals compare their ability and opinions with others after rating them in different levels (above or below) for the aim of self-evaluation, self-improvement, and self-enhancement (Rupp \& Cropanzano, 2002; Goodman \& Haisley, 2007; Kim et al., 2015).

Social comparisons takes two directions; upward with referents rated as above the evaluator level and downward with referents rated as below the evaluator level (Yperen, Brenninkmeijer, \& Buunk, 2006). This comparison produces feedback upon which individuals develop their perception about their abilities and opinions (Moon et al. 2017). This perception could be negative or positive and accordingly can create positive or negative affective status. It is this affective status that stimulates individuals' reactions to perceived justice (Collie et al., 2002). It is found that social comparison had a strong effect on performance judgments where individuals tend to use social comparisons feedback to evaluate their performance whereas they tend to use their existing self-knowledge to evaluate their ability (Moon, Lee, \& Oah, 2017; Schneider \& Valet, 2017). This means that employees' evaluation for their performance depends on the results of social comparisons, hence, it is expected that their future performance will be affected by this comparison (Goffin et al. 2009; Moon et al., 2017).

This research proposes that when individuals compare their inputs and outputs with others they develop a perception about how fair the organisation is, and this perception affects their performance (Goffin et al. 2009; Cohen \& Spector, 2001; Devonish \& Greenidge, 2010). It also proposes that the strength of this effect will be influenced by the social comparisons that an individual will conduct based on the contrast effect. If the social comparison results in negative feelings (e.g. in case of upward comparisons) the effect of perceived justice will be minimised (Greenberg et al. 2007; Schneider \& Valet, 2017) and accordingly individuals' willingness to reciprocate the organisation (through in-role performance and OCB) will be decreased (Spence et al. 2011). Whereas, these negative feelings may increase individuals' willingness to engage in CWB in case of perceived 
injustice (Saleem \& Gopinath, 2015).

On the other hand, if social comparison results in positive feelings (e.g. in case of downward comparisons) the effect of perceived justice will be maximized (Greenberg et al., 2007) and accordingly individuals' willingness to reciprocate the organisation will be increased (Spence et al., 2011). These positive feelings may decrease individuals' willingness to engage in CWB (Schneider \& Valet, 2017; Saleem \& Gopinath, 2015). This effect is represented in the following hypothesis:

H4: Social comparison orientation moderates the relationship between perceived organisational justice and employee performance.

\section{Methodology}

\subsection{Sample and Procedure}

This study targeted managers working in private and public organisations in different industries in Cairo-Egypt. 15 companies were selected. A formal letter was sent to the 15 companies but only 8 agreed to participate representing 3 industries ( 2 trading, 3 publishing and 3 contracting). Using statistical power test at $\alpha=0.05, \beta=$ 0.05 and power $=0.95$, for the targeted population $(\mathrm{N}=1521)$ a sample size of 310 is expected to be representative. A quota sampling procedure was used to recruit the sample from the eight organizations. Participants were approached in their offices and were asked to complete the questionnaire after assuring that their participation was voluntary and anonymity was guaranteed. Only 298 responded positively (186 from public organizations and 112 from private organizations) with a response rate of $(96.1 \%)$. $52 \%$ of respondents were male. The age ranged between 32 to $48(\mathrm{M}=39.64 \pm \mathrm{SD}=7.92)$. Years of experience ranged between 7 to 18 year $(\mathrm{M}=13.72 \pm \mathrm{SD}=5.36) .51 \%$ of the respondents were first line manager, $36 \%$ middle management, $13 \%$ top management. These characteristics indicate a reasonable mix of demographic groups represented in the collected data

\subsection{Measures}

Three-part questionnaire was used to assess the study variables. Organisational justice was measured using 20 items scale developed by Niehoff \& Moorman (1993) to assess distributive, procedural and interactional justice. Social comparison orientation was measured using the 11 item scale adapted from Gibbons \& Buunk (1999) to assess two social comparison orientations, namely, ability related comparison and opinion related comparison. However, as stated by Gibbons \& Buunk "although the two-factor structure emerged across numerous samples, a single-factor structure also fit the data fairly "(Gibbons \& Buunk, 1999, p.137). Accordingly the two orientations were treated as one factor representing individuals' tendency to socially compare. Employee performance was measured using 31-item scale to asses three main dimensions of performance, namely, in-role performance (7 items adapted from William \& Anderson, 1991), OCB (14 items adapted from William \& Anderson, 1991), and Counterproductive behaviour (10 items adapted from Spector, Bauer \& Fox, 2010). All scales' items were measured on a five-point Likert scale. Answers ranged from 1 (Strongly Disagree) to 5 (Strongly Agree). Finally, demographic variables including age, gender, managerial level, and experience were also assessed. To control the order of presenting questionnaire' items and to minimize respondents' tendency to provide positive answers (common method bias) the Latin square procedure was used.

Descriptive statistics and reliability coefficient of these measures are shown in table 1.

Table 1. Descriptive statistics and reliability coefficients of study variables

\begin{tabular}{lccc}
\hline Variable & Mean & SD & Cronbach's Alpha \\
\hline Performance & 119.19 & 15.88 & .865 \\
- In-role performance & 29.52 & 2.21 & .764 \\
- OCB & 60.22 & 2.58 & .787 \\
- CWB & 29.45 & 2.34 & .812 \\
Social comparison orientation & 48.53 & 9.99 & .889 \\
Organisational Justice & 62.74 & 9.87 & .875 \\
- Distributive $\quad 20.91$ & 3.76 & .729 \\
- Procedural & 23.21 & 2.48 & .756 \\
- Interactional & 16.50 & 3.17 & .818 \\
\hline
\end{tabular}

Furthermore, to test the validity of the used measures, two procedures were used. First, the three-part 
questionnaire was revised by a panel of 10 experts ( 5 academics and 5 from industry) who assessed the content of each part and evaluated the clearness and appropriateness of this content to the Egyptian culture. The experts indicated that the used questionnaires are clear, valid and culturally appropriate. Second, a confirmatory factor analysis, using AMOS 20, was conducted to confirm the factor structure of the used scales in the target population. The fit indices for these factor structures shown in table 2.

Table 2. Fit indices for the factor structures of the used instruments

\begin{tabular}{lllllll}
\hline Variable & CMIN/DF & GFI & AGFI & NFI & CFI & RMSEA \\
\hline In-role performance & 1.817 & .987 & .975 & .983 & .973 & .046 \\
OCB & 1.558 & .984 & .971 & .981 & .968 & .053 \\
Counterproductive behaviour & 1.196 & .986 & .977 & .984 & .971 & .049 \\
Social comparison orientation & 1.985 & .959 & .948 & .956 & .944 & .066 \\
Distributive Justice & 1.857 & .963 & .959 & .962 & .961 & .063 \\
Procedural Justice & 2.551 & .982 & .968 & .975 & .978 & .059 \\
Interactional Justice & 2.091 & .956 & .954 & .954 & .947 & .064 \\
Organisational Justice & 1.921 & .954 & .966 & .961 & .959 & .054 \\
\hline
\end{tabular}

As can be shown in the previous table, all fit indices were above the recommended level of acceptance (CMIN $/ \mathrm{df} \leq 3 / \mathrm{CFI}, \mathrm{IFI} \geq .95$ and SRMR, RMESA $<0.8$ ). Accordingly, it can be concluded that the factor structures of the used instruments are confirmed in the target population.

\section{Results}

To test the first three hypothesises assuming that there are significant relationships among organisational justice, in-role, OCB and CWB, Pearson correlation coefficients were calculated as shown in table 3.

Table 3. Person correlation for research variables

\begin{tabular}{|c|c|c|c|c|c|c|c|}
\hline Variable & 1 & 2 & 3 & 4 & 5 & 6 & 7 \\
\hline \multicolumn{8}{|l|}{ 1. In-role performance } \\
\hline 2. $\mathrm{OCB}$ & $.588 * *$ & & & & & & \\
\hline 3.Counterproductive behaviour & $-.357 * *$ & $-.378 * *$ & & & & & \\
\hline 4. Social comparison orientation & $.514 * *$ & $.420 * *$ & $-.428 * *$ & & & & \\
\hline 5. Distributive Justice & $.214^{* *}$ & $.352 * *$ & $-.316 * *$ & .132 & & & \\
\hline 6. Procedural Justice & $.232 * *$ & .128 & $-.371 * *$ & .164 & $.597 * *$ & & \\
\hline 7. Interactional Justice & $.555 * *$ & $.588 * *$ & $-.308 * *$ & .121 & $.516^{* *}$ & $.574 * *$ & \\
\hline 8. Organisational justice & $.425^{* *}$ & $.395 * *$ & $-.275^{*}$ & .157 & $.612 * *$ & $.745^{* *}$ & $.657^{* *}$ \\
\hline
\end{tabular}

** Coefficient is significant at .01 level; $* * *$ Coefficient is significant at .001 level.

As shown in table 3 Organisational justice has a significant positive correlation with both in-role performance and OCB and significant negative correlation with CWB. The three dimensions of organisational Justice also have significant correlation with the three dimensions of performance except for procedural justice that has correlation with in-role and CWB behaviours and not with OCB. CWB has significant negative correlation with the three dimensions of OJ. Hence, the first three hypothesises are supported.

To test the fourth hypothesis, assuming that social comparison orientation moderates the relationship between organisational justice and the three dimensions of employees' performance, multiple regression analysis with the interaction effect between the standardized scores of organisational justice and social comparison orientation was 
conducted as shown in table 4.

Table 4. The moderation effect of social comparison orientation

\begin{tabular}{lllllll}
\hline Dependent & Variable & $\mathrm{b}$ & $S . E$ & $\mathrm{~T}$ & $\mathrm{R}^{2}$ & $\mathrm{~F}$ \\
\hline Employee' & Z -Social Comparison Orientation (SCO) & 2.66 & .513 & $5.18^{* *}$ & .342 & $51.76^{* *}$ \\
performance & Z - Organisational Justice (OJ) & 2.84 & .424 & $6.69^{* *}$ & & \\
& Interaction SCO * OJ & 1.21 & .441 & $2.75^{* *}$ & & \\
In-role & Z -Social Comparison Orientation (SCO) & 2.75 & .621 & $4.43^{* *}$ & .383 & $54.38^{* *}$ \\
Performance & Z - Organisational Justice (OJ) & 2.91 & .584 & $4.98^{* *}$ & & \\
& Interaction SCO * OJ & 1.64 & .433 & $3.78^{* *}$ & & \multirow{2}{*}{$52.71^{* *}$} \\
OCB & Z -Social Comparison Orientation (SCO) & 2.61 & .588 & $4.44^{* *}$ & .357 & \\
& Z - Organisational Justice (OJ) & 2.45 & .432 & $5.67^{* *}$ & & \\
& Interaction SCO * OJ & 1.56 & .356 & $4.38^{* *}$ & & \multirow{2}{*}{$48.87^{* *}$} \\
CWB & Z -Social Comparison Orientation (SCO) & -2.55 & .476 & $5.35^{* *}$ & .339 & \\
& Z - Organisational Justice (OJ) & -1.98 & .562 & $3.52^{* *}$ & & \\
& Interaction SCO * OJ & -1.74 & .612 & $2.84^{* *}$ & & \\
\hline
\end{tabular}

* Coefficient is significant at .05 level; ** Coefficient is significant at .01 level.

The multiple regression analysis indicates that there is a significant interaction between organisational justice and social comparison orientation that affect employees' performance. SCO also has significant interaction with each one of the three dimensions of employees' performance namely; in-role performance, OCB, and CWB. This result suggests that $\mathrm{SCO}$ moderate the relationship between organisational justice and employees' performance dimensions. Therefore, the fourth hypothesis is also supported.

\section{Discussion}

Results supported the significant relationship between OJ and the three dimensions of performance. With regard to the three dimensions of OJ, research results found that distributive justice have significant correlation with all three dimensions of performance which is supported by previous researches (Saleem \& Gopinath, 2015; Zapata-Phelan et al. 2009). Hence, according to research results when employees perceive that outcomes were distributed fairly they tend to reciprocate the organisation by achieving expected levels of in-role performance and participate in OCB (Blakely et al. 2005). Whereas, perceived distributive injustice could increase employees' involvement in CWB (Chernyak-Hai \& Tziner, 2014).

Yet, this result contradicts with other researches where distributive justice did not have significant relation with task performance (Williams, 1999) or OCB (Lambert \& Hogan, 2013). The insignificant relation found in Williams' experimental research (1999) could be understood by employees' tendency to maintain the same level of income, so they tend not to reduce their in-role performance (Aryee et al., 2002). Researchers also argue that distributive justice can only lead to performing the required tasks, but can't lead to loyalty that motivate employees to engage effectively in OCB which could explain the results found in Lambert and Hogan' research (2013).

However, this contradiction opens the door for more investigation with different methodologies. As far as the authors' knowledge, this relationship was rarely investigated using longitudinal methods which could add more understanding for the interaction between distributive justice and performance dimensions over time.

Results also show significant positive relation between procedural justice and in-role performance. When employees trust the fairness of procedures used for evaluation and outcome distribution, they perceive that their efforts will be fairly acknowledged so they try to satisfy requirements of their duties (Devonish \& Greenidge, 2010). This result supports previous findings (Burney et al., 2009). On the other hand, procedural justice has a significant negative relation with CWB which supports the argument that employees seek revenge for perceived procedural injustice by involving in behaviours that harm the organisation (Jones, 2009; Chernyak-Hai \& Tziner, 2014).

However, no significant relation is found between procedural justice and $\mathrm{OCB}$ which matches the results found by Williams (1999) and contradicts with other research where procedural justice has significant relation with OCB in general (Lambert \& Hogan, 2013; Devonish \& Greenidge, 2010) and with OCB directed to the organisation specifically (Jones, 2009). Dijke, Cremer, Mayer \& Quaquebeke (2012) argue that for procedural justice to affect OCB, leadership style should be considered. They argue that without good empowerment from leadership to employees, perceived procedural justice will have small effect on OCB (Dijke et al. 2012). This 
matches also the argument that Leader-Member Exchange mediate the relationship between procedural justice and OCB (Burton et al. 2008).

Accordingly, it might be the relationship with leaders that affected this relation. This argument is supported by the explanation given by Konovsky (2000) for the nature of procedural justice. According to Konovsky, when employees do not trust the leaders they will doubt the execution of fair procedures even if they believe that the procedures themselves are fair. If we consider the interrelation between interactional justice and procedural justice (Colquitt et al. 2001) and with the relatively low level of perceived interactional justice found in results $(\mathrm{M}=16.50, \mathrm{SD}=3.17)$, we may conclude that the reason for the insignificant relation between procedural justice and OCB lays in the degree of trust in leaders. Though, more research is needed to clarify the interaction between procedural justice, interactional justice, trust in leaders and OCB.

As for interactional justice, significant positive relation is found with in-role performance and OCB, whereas significant negative relation is found with CWB. These results match those of previous research where interactional justice predicted in-role performance and OCB (Devonish \& Greenidge, 2010; Jones, 2009). Employees perceive interactional justice when they are treated respectfully, with dignity, and receive all necessary information (Colquitt et al. 2001). According to these results, interactional justice has significant negative relation with CWB. This also supports previous research (Saleem \& Gopinath, 2015; Devonish \& Greenidge, 2010). Interactional justice affects employees' psychological statues and cause stress and anger that motivate employees to get revenge by attempting to harm the perceived source of injustice (Wu et al. 2016; Or \& Aharon, 2017).

With regard to organisational justice in total, research results also find significant positive relationship between organisational justice and the positive side of employees' performance represented in OCB and in-role performance, whereas it has significant negative relationship with CWB among Egyptian managers in the studied sample. This supports the justice -performance relationship found in literature (Swalhi et al. 2017; Devonish \& Greenidge, 2010) and supports the results found in similar cultures like Saudi Arabia and Jourdan where organisational justice was found to significantly affect OCB (Elamin \& Tlaiss, 2015; Al-Quraan \& Khasawneh, 2017). However, to the best of authors' knowledge this current research is the first research that investigates the effect of perceived organisational justice on the three dimensions of performance within an Arab context. It is within research aims to contribute to the literature by testing the significance of organisational justice-performance relationship in new context using the three dimensions of performance.

This research proposes moderation role of social comparison orientation in the justice-performance relationship based on the fact that individuals unavoidably compare with others in their organizations (Rupp \& Cropanzano, 2002; Buunk et al. 2005), and the results of this comparison will affect their reaction to the perceived organisational justice / injustice (Yperen et al. 2006; Moon et al. 2017). According to research results social comparison orientation moderated the relationship between perceived organisational justice and employees' performance with its three dimensions. This result supports the proposed moderation role of social comparison orientation. To the best of authors' knowledge there is no previous attempt to test this moderation effect on the justice - performance (in-role, OCB, CWB) relationship. However, evidence from the literature can be found in researches that linked performance to social comparisons (Spence et al. 2011).

In their experimental study Gächter and Thöni (2010) found a significant effect for wage comparison on performance depending on whether the discrimination in wages is perceived as intentional or non-intentional where employees apply the vertical comparisons (upward and downward). Others examined the effect of social comparisons on the relation between leader-member exchange (LMX) and in-role performance, OCB and job satisfaction, where employees compare their LMX with others and produce relative LMX. This relative LMX has significant effects on performance and satisfaction with a mediating role for self-efficacy (Hu \& Liden, 2013). Another study (Moon et al. 2017) supported the effect of social comparison on performance in an experiment that compared the effect of social comparison feedback and objective feedback. Social comparisons were also found to affect teachers' performance within the effort-performance expectancy framework (Yperen et al., 2006).

On the other hand, according to research results there is no significant relationship between social comparisons and perceived justice. This is supported by previous research where knowledge about others outcomes -within the social comparison process- did not affect perceived interactional and procedural justice (Collie et al. 2002). In contrast, it was found that social comparison orientations moderate the link between relative earnings and justice perceptions, where Individuals' perceived justice toward their relative wages was moderated by their tendency to compare (Schneider \& Valet, 2017). Social comparisons also affected perceived distributed justice 
within East Asia countries where employees' level of materialism mediated the relationship (Kim et al. 2015). This contradiction could be attributed to the existence of performance in the current research. It seems that the link between performance and social comparison orientation is stronger and affects the strength of the justice-performance relationship. This also supports the moderation effect of social comparison. However, more research is needed to investigate this moderation effect in different contexts and with different methodologies.

\section{Conclusion}

This study aimed at investigating the relationship between organisational justice and an integrated model of employees' performance that include; in-role performance, citizenship behaviours, and counterproductive behaviours within the Egyptian context. The study also aimed at testing the moderation effect of social comparison orientation on the justice - performance relationship.

The results revealed relatively high levels of perceived procedural and distributive justice and low levels of interactional justice among Egyptian managers. A significant positive relationship was found between procedural and interactional justice and the positive side of performance presented with in-role performance and OCB. Whereas, procedural justice has a positive significant relationship with in-role performance only. CWB has significant negative effect with the three dimensions of justice. The justice - performance relation was supported in the selected sample. Results also supported the moderation effect of social comparison orientation in the justice -performance relationship with the integrated model of performance.

Practical Implications. Research results indicate several practical implications. First, reasons for perceived low interactional justice among Egyptian managers in the selected sample needs to be investigated especially with the relatively strong relationship found with CWB. Second, the significant relations found between justice and the three performance dimensions raise the need for new performance measure to be applied in organisations to catch the three dimensions. Third, providing information regarding the performance evaluation criteria and about referents is very important as it will help in increasing employees' tendency to conduct unbiased social comparison (Goodman \& Haisley, 2007). Finally, taking into consideration the effect of social comparison orientation can add not only more insight for understanding motivations behind employees' performance, but also good base for designing performance appraisal systems in organisations (Goffin et al. 2009).

Theoretical Implications. First, Regardless of the national differences, the organisational justice- performance relationship is supported within the Egyptian context. Second, the significant effects found for perceived justice -especially distributive and interactional - on the three dimensions of performance add to the justice theory by pinpointing the importance of applying the performance integrated framework when examining the effects of justice. Studying only one dimension of performance may exclude the interactional effects found between the three dimensions of performance (Dalal, 2005; Devonish \& Greenidge, 2010). Third, based on the moderation effect found for social comparison orientation, employees' reactions to injustice can be controlled or managed if the frequency and direction of social comparison is controlled. Yet, this does not eliminate the fact that individuals may seek many goals through social comparison and that social environment may impose unwanted comparisons (Moon et al. 2017).

Limitations. These results are subject to the following limitations. (1) The size and nature of the sample could be helpful in the Egyptian context but may also limit the generalizability of the results in other contexts. (2) The applied methodology is helpful for exploratory and explanatory research, yet, applying different methodologies (experimental / longitudinal) could add more insight to the topic.

Future Research. It is recommended for future research to consider; (1) the effect of information on social comparison and how this will affect employees' outcomes. (2) The interaction between distributive justice and performance dimensions over time. (3) The interaction between organisational justice dimensions, trust in leaders and OCB. (4) The moderation effect or SCO in different context and with different methodologies

\section{References}

Al-Quraan, A. B., \& Khasawneh, H. I. (2017). Impact of Organizational Justice on Organizational Citizenship Behaviour: Case Study at Jordan National Electric Power Company. European Journal of Business and Management, $\quad 9, \quad 215-229$ Retrieved from https://www.researchgate.net/publication/317304401_Impact_of_Organizational_Justice_on_Organizational _Citizenship_Behavior_Case_Study_at_Jordan_National_Electric_Power_Company

Aryee, S., Budhwar, P. S., \& Chen, Z. X. (2002). Trust as a Mediator of the Relationship between Organizational Justice and Work Outcomes: Test of a Social Exchange Model. Journal of Organizational Behaviour, 23, 267-285. Retrieved from http://www.jstor.org/stable/4093804 
Blakely, G. L., Andrews, M. C., \& Moorman, R. H. (2005). The Moderating Effects of Equity Sensitivity on the Relationship between Organizational Justice and Organizational Citizenship Behaviours. Journal of Business and Psychology, 20, 259-273. https://doi.org/10.1007/s10869-005-8263-3

Burney, L. L., Henle, C. A., \& Widener, S. K. (2009). A path model examining the relations among strategic performance measurement system characteristics, organizational justice, and extra- and in-role performance. Accounting, Organizations and Society, 34, 305-321. https://doi.org/10.1016/j.aos.2008.11.002

Burton, J. P., Sablynski, C. J., \& Sekiguch, T. (2008). Linking Justice, Performance, and Citizenship via Leader-Member Exchange. Journal of Business and Psychology, 23, 51-61. https://doi.org/10.1007/s10869-008-9075-z

Buunk, B. P., Zurriaga, R., \& Peíró, J. M. (2005). Social Comparisons at Work as Related to a Cooperative Social Climate and to Individual Differences in Social Comparison Orientation. Applied Psychology: An International Review, 54, 61-80.

Chernyak-Hai, L., \& Tziner, A. (2014). Relationships between counterproductive work behaviour, perceived justice and climate, occupational status, and leader-member exchange. Journal of Work and Organizational Psychology, 30, 1-12. doi:http://dx.doi.org/10.5093/tr2014a1

Cohen, Ch. Y., \& Spector, P. E. (2001). The Role of Justice in Organizations: A Meta-Analysis. Organizational Behaviour and Human Decision Processes, 86, 278-321. https://doi.org/10.1006/obhd.2001.2958

Collie, T., Bradley, G., \& Sparks, B. A. (2002). Fair process revisited: Differential effects of interactional and procedural justice in the presence of social comparison information. Journal of Experimental Social Psychology, 38, 545-555.

Colquitt, J. A., Conlon, D. E., Wesson, M. J., Porter, C. O., \& Ng, K. Y. (2001). Justice at the millennium: a meta-analytic review of 25 years of organizational justice research. Journal of Applied Psychology, 86, 425-445. https://doi.org/10.1037/0021-9010.86.3.425

Dalal, R. S. (2005). A Meta-Analysis of the Relationship between Organizational Citizenship Behaviour and Counterproductive Work Behaviour. Journal of Applied Psychology, 90, 1241-1255. https://doi.org/10.1037/0021-9010.90.6.1241

Devonish, D., \& Greenidge, D. (2010). The Effect of Organizational Justice on Contextual Performance, Counterproductive Work Behaviours, and Task Performance: Investigating the moderating role of ability-based emotional intelligence. International Journal of Selection and Assessment, 18, 75-86.

Dijke, M. v., Cremer, D. D., Mayer, D. M., \& Quaquebeke, N. V. (2012). When does procedural fairness promote organizational citizenship behaviour? Integrating empowering leadership types in relational justice models. Organizational Behaviour and Human Decision Processes, 117, 235-248. https://doi.org/10.1016/j.obhdp.2011.10.006

Elamin, A. M., \& Tlaiss, H. A. (2015). Exploring the relationship between organizational citizenship behaviour and organizational justice in the Islamic Saudi Arabian context. Employee Relations, 37, 2-29. Retrieved from https://doi.org/10.1108/ER-03-2014-0033

Festinger, L. (1954). A Theory of Social Comparison Processes. Human Relations, 7, 117-140. https://doi.org/10.1177/001872675400700202

Gächter, S., \& Thöni, C. (2010). Social comparison and performance: Experimental evidence on the fair wage-effort hypothesis. Journal of Economic Behaviour \& Organization, 76, 531-543. https://doi.org/10.1016/j.jebo.2010.08.008

Gibbons, F. X., \& Buunk, B. P. (1999). Individual Differences in Social Comparison: Development of a Scale of Social Comparison Orientation. Journal of Personality and Social Psychology, 76, 129-142.

Goffin, R. D., Jelley, R. B., Powell, D. M., \& Johnston, N. G. (2009). Taking Advantage of Social Comparisons in Performance Appraisal: The Relative Percentile Method. Human Resource Management, 48, 251-268. https://doi.org/10.1002/hrm.20278

Goodman, P. S., \& Haisley, E. (2007). Social comparison processes in an organizational context: New directions. Organizational Behaviour and Human Decision Processes, 102, 109-125. https://doi.org/10.1016/j.obhdp.2006.10.005

Greenberg, J., Ashton-James, C. E., \& Ashkanasy, N. M. (2007). Social comparison processes in organizations. Organizational Behaviour and Human Decision Processes, 102, 22-41. 
Griffin, M. A., Neal, A., \& Parker, S. K. (2007). A New Model of Work Role Performance: Positive Behavior in Uncertain and Interdependent Contexts. The Academy of Management Journal, 50, 327-347. Retrieved from http://www.jstor.org/stable/20159857

Guimond, S., Chatard, A., Martinot, D., Crisp, R. J., \& Redersdorff, S. (2006). Social Comparison, Self-Stereotyping, and Gender Differences in Self-Construal. Journal of Personality and Social Psychology, 90(2), 221-242. https://doi.org/10.1037/0022-3514.90.2.221

Hu, J., \& Liden, R. C. (2013). Relative Leader-Member Exchange within Team Contexts: How and when Social Comparison impacts Individual Effectiveness. Personnel Psychology, 66, 127-172. https://doi.org/10.1111/peps.12008

Jones, D. A. (2009). Getting even with one's supervisor and one's organization: relationships among types of injustice, desires for revenge, and counterproductive work behaviours. Journal of Organizational Behaviour, 30, 525-542. https://doi.org/10.1002/job.563

Kelloway, E. K., Francis, L., Prosser, M., \& Cameron, J. E. (2010). Counterproductive Work Behaviour as protest. Human Resource Management Review, 20, 18-25. https://doi.org/10.1016/j.hrmr.2009.03.014

Kim, T. Y., Edwards, J. R., \& Shapiro, D. L. (2015). Social Comparison and Distributive Justice: East Asia Differences. Journal of Business Ethics, 132, 401-414. https://doi.org/10.1007/s10551-014-2326-1

Konovsky, M. A. (2000). Understanding Procedural Justice and Its Impact on Business Organizations. Journal of Management, 26, 489-511.

Lambert, E. G., \& Hogan, N. L. (2013). The Association of Distributive and Procedural Justice with Organizational Citizenship Behaviour. The Prison Journal, 93, 313-334. https://doi.org/10.1177/0032885513490491

LePine, J. A., Erez, A., \& Johnson, D. E. (2002). The nature and dimensionality of organizational citizenship behavior: A critical review and meta-analysis. Journal of Applied Psychology, 87, 52-65. https://doi.org/10.1037//0021-9010.87.1.52

Miles, D. E., Borman, W. E., Spector, P. E., \& Fox, S. (2002). Building an Integrative Model of Extra Role Work Behaviours: A Comparison of Counterproductive Work Behaviour with Organizational Citizenship Behaviour. International Journal of Selection and Assessment, 10, 51-57. https://doi.org/10.1111/1468-2389.00193

Moon, K., Lee, K., Lee, K., \& Oah, S. (2017). The Effects of Social Comparison and Objective Feedback on Work Performance across Different Performance Levels. Journal of Organizational Behaviour Management, 37, 63-74. http://dx.doi.org/10.1080/01608061.2016.1236059

Niehoff, B. P., \& Moorman, R. H. (1993). Justice as a Mediator of the Relationship between Methods of Monitoring and Organizational Citizenship Behaviour. The Academy of Management Journal, 36, 527-556. Retrieved from http://www.jstor.org/stable/256591

Nowakowski, J. M., \& Conlon, D. E. (2005). Organizational Justice: Looking Back, Looking Forward. International Journal of Conflict Management, 16, 4-29.

Or, S., \& Aharon, T. (2017). The Mediating and Moderating Role of Burnout and Emotional Intelligence in the Relationship between Organizational Justice and Work Misbehaviour. Journal of Work and Organizational Psychology, 33, 157-164. https://doi.org/10.1016/j.rpto.2017.05.002

Organ, D. W., Podsakoff, P. M., \& MacKenzie, S. B. (2006). Organizational Citizenship Behaviour: Its Nature, Antecedents, and Consequences. California: Sage Publications.

Robinson, S. L., \& Bennett, R. J. (1995). A Typology of Deviant Workplace Behaviours: A Multidimensional Scaling Study. The Academy of Management Journal, 38, 555-572. https://doi.org/10.2307/256693

Rotundo, M., \& Sackett, P. R. (2002). The Relative Importance of Task, Citizenship, and Counterproductive Performance to Global Ratings of Job Performance: A Policy-Capturing Approach. Journal of Applied Psychology, 87, 66-80. https://doi.org/10.1037//0021-9010.87.1.66

Rupp, D. E., \& Cropanzano, R. (2002). The mediating effects of social exchange relationships in predicting workplace outcomes from multifoci organizational justice. Organizational Behaviour and Human Decision Processes, 89, 925-946.

Sackett, P. R. (2002). The Structure of Counterproductive Work Behaviours: Dimensionality and Relationships 
with Facets of Job Performance. International Journal of Selection and Assessment, 10, 5-11.

Sackett, P. R., Berry, C. M., Wiemann, S. A., \& Laczo, R. M. (2009). Citizenship and Counterproductive Behaviour: Clarifying Relations between the Two Domains. Human Performance, 19, 441-464. http://dx.doi.org/10.1207/s15327043hup1904_7

Saleem, F., \& Gopinath, C. (2015). Injustice, Counterproductive Work Behaviour and mediating role of Work Stress. Pakistan Journal of Commerce and Social Sciences, 9, 683-699.

Schneider, S. M., \& Valet, P. (2017). Relative Standards and Distributive Justice: How Social Comparison Orientations Moderate the Link between Relative Earnings and Justice Perceptions. Social Psychology Quarterly, 80, 276-287. https://doi.org/10.1177/0190272517708810

Spector, P. E., \& Fox, S. (2010). Theorizing about the deviant citizen: An attributional explanation of the interplay of organizational citizenship and counterproductive work behaviour. Human Resource Management Review, 20, 132-143. https://doi.org/10.1016/j.hrmr.2009.06.002

Spence, J. R., Ferris, D. L., Brown, D. J., \& Heller, D. (2011). Understanding daily citizenship behaviours: A social comparison perspective. Journal of Organizational Behaviour, 32, 547-571. https://doi.org/10.1002/job.738

Swalhi, A., Zgoulli, S., \& Hofaidhllaoui, M. (2017). The influence of organizational justice on job performance: The mediating effect of affective commitment. Journal of Management Development, 36, 542-559. https://doi.org/10.1108/JMD-11-2015-0162

Williams, L. J., \& Anderson, S. E. (1991). Job satisfaction and organizational commitment as predictors of organizational citizenship and in-role behaviours. Journal of Management, 17, 601-617.

Williams, S. (1999). The Effects of Distributive and Procedural Justice on Performance. Journal of Psychology, 133, 183-194.

Wu, M., Sun, X., Zhang, D., \& Wang, C. (2016). Moderated mediation model of relationship between perceived organizational justice and counterproductive work behaviour. Journal of Chinese Human Resource Management, 7, 64-81. Retrieved from https://doi.org/10.1108/JCHRM-07-2016-0016

Yperen, N. W., Brenninkmeijer, V., \& Buunk, A. P. (2006). People's responses to upward and downward social comparisons: The role of the individual's effort-performance expectancy. British Journal of Social Psychology, 45, 519-533. https://doi.org/10.1348/014466605X53479

Zapata-Phelan, C. P., Colquitt, J. A., Scott, B. A., \& Livingston, B. (2009). Procedural justice, interactional justice, and task performance: The mediating role of intrinsic motivation. Organizational Behaviour and Human Decision Processes, 108, 93-105. https://doi.org/10.1016/j.obhdp.2008.08.001

\section{Copyrights}

Copyright for this article is retained by the author(s), with first publication rights granted to the journal.

This is an open-access article distributed under the terms and conditions of the Creative Commons Attribution license (http://creativecommons.org/licenses/by/4.0/). 